\title{
Postpartum Depression: Making the Case for Routine Screening
}

\author{
Aaron Keshen* B.Sc, and Joanne L. MacDonald M.D.
}

\section{CASE REPORT}

Mrs. $R$ is a 29-year-old woman primipara who presents for a routine check-up 6 weeks postpartum. Her history and physical are unremarkable except that during the past month she has found it harder to concentrate on simple tasks, such as making the baby's formula. Also, despite always feeling exhausted, she has been having trouble falling asleep after the baby has been put to sleep. When questioned about her mood, she replies, "I feel fine", but offers little else. You know that these complaints may be symptoms of postpartum depression (PPD), but because they are non-specific, often nonpathologic (especially postpartum) and she denies feeling depressed, you are not sure whether the clinical presentation warrants a more thorough investigation of Mrs. R's mental state. Should you investigate more thoroughly? If so, instead of taking a lengthy psychiatric history, what fast and effective methods could be used to explore the possibility that this patient has, or is at risk of developing PPD? Also, what are the current guidelines for diagnosing and treating PPD?

\section{DISCUSSION}

At least $10 \%$ of mothers will suffer from postpartum depression (PPD) $(1,2,3)$ a debilitating condition that is defined as a Major Depressive Episode, which has an onset within 4 weeks postpartum (See Table 1 for the DSM-IV4 diagnostic criteria and differential diagnosis for PPD). Although clinicians have come to accept the view that PPD is a common and serious medical condition, they are still debating the ideas concerning the etiology of the illness. Biological theorists have suggested that postpartum fluctuations in hormones

*To whom correspondence should be addressed: Aaron Keshen, 1041 Wellington St., \#400, Halifax, NS, B3H 4P5; Telephone: (902)-4442997; Email: akeshen@hotmail.com and/or other biological factors are responsible for causing PPD $(1,2,3)$ Psychological models have also attempted to explain the etiology of PPD. For instance, the cognitive model suggests that factors such as low self-esteem and dysfunctional relationships predispose the mother to depression, which is then precipitated by postpartum stress (1). Although evidence exists for both biological and psychological theories, conflicting data has made it impossible to definitively claim that any one of these theories is alone capable of explaining the etiology of PPD (1). Instead, research suggests that a multifactorial etiology, which includes both biological and psychological factors, is probably responsible for the illness (8).

While the etiology of PPD is still debated, the implications of accurately diagnosing the condition remains important for the immediate and long-term mental health of the mother (1), her spousal relationship (1) and even the cognitive and behavioral development of her child $(1,2)$. Since PPD detrimentally affects so many lives, it is unfortunate that many cases go undiagnosed $(1,2)$. One major reason for under diagnosis is that many physicians only inquire casually about a new mother's mental state $(1,2)$ In addition, there are several reasons why some mothers with PPD will not disclose their symptoms. One reason is that there is still a stigma surrounding mental illness. Another reason is that some women harbor guilt about feeling depressed during a period when they are expected to be blissful (1). Yet another reason is that some women assume that they should experience some physiological changes (e.g. insomnia) during the first few postpartum months, and are therefore embarrassed to "complain" about certain symptoms to their family doctors (16).

Since it is beneficial for physicians to explore the issue of PPD more thoroughly, what fast and effective 
Table 1. Diagnosing Postpartum Depression

\section{Definition of PPD:}

The DSM-IV4 defines PPD as a Major Depressive Episode*, which has an onset within 4 weeks postpartum. In order for the diagnosis to be made at least five of the symptoms (see Box 1) must be present, one of which must be depressed mood or diminished pleasure or interest in activities. The symptoms must be present most of the day nearly every day for two weeks. Also, there must be an associated decline in social and /or occupational functioning.

\section{Differential Diagnosis of PPD:}

\section{Baby Blues:}

In order for the diagnosis of PPD to apply, the DSM-IV criteria must be met for 2 consecutive weeks.4 If the symptoms are observed for less than 2 weeks, then a diagnosis of "baby blues" is more appropriate.16 "Baby blues", which is experienced by approximately $80 \%$ of new mothers, usually lasts for hours to days, and in most cases resolves spontaneously by the 10th postnatal day.

\section{Postpartum Psychosis:}

Postpartum psychosis is a medical emergency that affects about 0.2 percent of new mothers. 16 Symptoms usually begin by the first postpartum month and resemble those seen during a manic episode (i.e. insomnia, agitation, irritable mood, hallucinations and delusions). 4 If hallucinations and/or delusions are present they often involve the infant, and can lead to harm directed towards self or the infant.

General Medical Conditions that Present like Depression:

In particular, thyroid disorder and anemia can be exacerbated postpartum, and should therefore be ruled out with a careful history, physical, and appropriate laboratory tests.

\section{Suicide Risk Assessment:}

As with other forms of depression, the risk of suicide is increased for women with PPD.16 For this reason, it is essential to determine whether a patient with PPD is considering suicide. The first step in a suicide risk assessment should be inquiring about passive ideation . One way to do this is by asking, "Have you felt so low that you've thought life is not worth living?" If an affirmative answer is given, the active intent/plan should be determined. This can be done by asking, "Have you ever thought of how you might end your life?" or "what types of things have you considered doing?" If the patient does have active intent, you should ask whether they have the means to carry out the plans they have devised. If you are concerned that a patient is a suicide risk, you should insist that they go to the hospital for psychiatric evaluation. If they refuse, and you suspect they are truly a threat to themselves, you must notify the authorities.

\section{Symptoms4 of PPD*}

" Depressed mood

" Diminished pleasure or interest in activities

" Sleep disturbance (insomnia or hypersomnia)

" Weight loss or weight gain

" Psychomotor agitation or retardation

" Loss of energy

" Feelings of worthlessness or inappropriate guilt

" Diminished concentration, or indecisiveness

" Frequent thoughts of death or suicide

*See the DSM-IV4 for a more detailed description of the diagnostic criteria and symptoms of depression.

methods can be used to accomplish this goal? Two accepted approaches that can be used concomitantly are: a) routine screening of all postpartum mothers and b) heightened attention to the risk factors for PPD. The next section of this paper describes how these two methods can be used effectively to increase the detection of this devastating disease.

\section{Routine Screening and Risk Factors for PPD}

One way for physicians to explore the issue of PPD is to routinely screen all postpartum mothers, a procedure that is very easy and effective, but for unknown reasons is almost never used (1). Among various screening tests for PPD, experts consider the Edinburgh Postnatal Depression Scale (EPDS) (1) to be the best choice in terms of its ease of administration, validity, specificity and sensitivity $(16,19,1,2,38)$ (See Table 2 for the EPDS scale and guidelines for raters.) This scale has been validated using standardized psychiatric interviews and translated into fourteen languages (19,1,2,3). Furthermore, evidence from four studies has confirmed that the tool is approximately $86 \%$ sensitive and $90 \%$ specific for PPD. These are impressive statistics when one considers that the test consists of only 10 multiple choice questions and takes mothers less than 5 minutes to complete $(16,19)$. As further evidence of the scale's effectiveness, one study showed that routine screening with the EPDS in family practices increased the rate of diagnosis of PPD from $3.7 \%$ to $10.7 \%$ (18)

In addition to routinely screening postpartum mothers, 
Table 2. Edinburgh Postnatal Depression Scale (EPDS)19 and Guidelines for Raters

Guidelines for Raters (19)

1. The mother is asked to underline the response which comes closest to how she has been feeling in the previous 7 days.

2. All ten items must be completed.

3. Care should be taken to avoid the possibility of the mother discussing her answers with others.

4. The mother should complete the scale herself, unless she has limited English or has difficulty with reading.

The child health clinic, postnatal check-up or a home visit may provide suitable opportunities for its completion.

\section{Scoring the EPDS}

Response categories are scored $0,1,2$, and 3 according to increased severity of the symptoms. Items marked with an asterisk are reverse scored (i.e. 3, 2, 1, and 0). The total score is calculated by adding together the scores for each of the ten items. Individual items are totalled to give an overall score. A score of 12+ indicates the likelihood of depression (with about $90 \%$ specificity and $86 \%$ sensitivity), but not its severity $(19,22,23,24)$. If a women scores $12+$, this warrants a full psychiatric history during which a DSM-IV diagnosis of PPD is considered. A woman who scores 5-11 should be evaluated again in 2-4 weeks in order to assess whether there has been a worsening of symptoms. A patient who scores less than 12 on the EPDS, but scores 3 or 2 on Question 10 warrants a full psychiatric evaluation. The EPDS Score is designed to assist, not replace clinical judgement.

Users may reproduce the scale without further permission providing they respect copyright by quoting the names of the authors, the title and the source of the paper in all reproduced copies.

\section{Edinburgh Postnatal Depression Scale19}

As you have recently had a baby, we would like to know how you are feeling. Please UNDERLINE the answer which comes closest to how you have felt IN THE PAST 7 DAYS, not just how you feel today.

1. I have been able to laugh and see the funny side of things.

As much as I always could

Not quite so much now

Definitely not so much now

Not at all

2. I have looked forward with enjoyment to things.

As much as I ever did

Rather less than I used to

Definitely less than I used to

Hardly at all

3. * I have blamed myself unnecessarily when things went wrong.

Yes, most of the time

Yes, some of the time

Not very often

No, never

4. I have been anxious or worried for no good reason.

No, not at all

Hardly ever

Yes, sometimes

Yes, very often

5. * I have felt scared or panicky for not very good reason.

Yes, quite a lot

Yes, sometimes

No, not much

No, not at all
6. * Things have been getting on top of me.

Yes, most of the time I haven't been able to cope at all

Yes, sometimes I haven't been coping as well as usual

No, most of the time I have coped quite well

No, I have been coping as well as ever

7. * I have been so unhappy that I have had difficulty sleeping.

Yes, most of the time

Yes, sometimes

Not very often

No, not at all

8. * I have felt sad or miserable.

Yes, most of the time

Yes, quite often

Not very often

No, not at all

9. * I have been so unhappy that I have been crying.

Yes, most of the time

Yes, quite often

Only occasionally

No, never

10. * The thought of harming myself has occurred to me.

Yes, quite often

Sometimes

Hardly ever

Never

(Taken from the British Journal of Psychiatry, June, 1987, Vol. 150 by J.L. Cox, J.M. Holden, R. Sagovsky) 
physicians can further explore the possibility of PPD by asking patients about the risk factors for the illness. This is an effective strategy because certain risk factors are very strong predictors of whether a patient is susceptible to PPD (33-37). Some important risk factors for physicians to keep in mind are included in Table 3.

Table 3. Risk Factors for PPD

History of depression prior to conceiving (3).

History of PPD in previous pregnancies (3).

Family history of depression (32).

Few supportive family members or friends (3).

Financial or housing difficulties (3).

Severe premenstrual syndrome (35).

Dysfunctional spousal relationship $(34,3)$.

Other stressful life events during the pregnancy or after the childbirth (3).

\section{Management of PPD}

The management of PPD parallels that of Major Depressive Disorder; however, there are some special management considerations for patients with PPD $(1,2,3,4,5)$. Some of these considerations are described in Table 4.

\section{Case Revisited}

Since casual inquiry may not reveal PPD symptoms that Mrs. R could be experiencing, you decide to investigate her complaints more thoroughly. You screen Mrs. R using the EPDS and she has a score of 14, which suggests that there is a $90 \%$ probability that she suffers from PPD. She also has several of the risk factors for the condition (i.e. marital discord and financial difficulties), which corroborates the positive EPDS score. Because of the high probability that Mrs. R has PPD you take a detailed psychiatric history during which you apply the DSM-IV criteria of PPD, and also rule out disorders that present like PPD.

You determine that she does in fact have moderate PPD, so you recommend SSRI antidepressant administration, with follow-up within 2 weeks to assess side effects and response. As well, you provide her and her husband with patient education materials. You also initiate or make a

Table 4. Management of PPD

\begin{tabular}{|c|c|}
\hline $\begin{array}{l}\text { Mild PPD } \\
\text { Symptoms that barely fulfill the DSM-IV diagnostic criteria for } \\
\text { PPD and cause a minor impairment of social/occupational } \\
\text { functioning. }\end{array}$ & $\begin{array}{l}\text { Moderate/Severe PPD } \\
\text { Symptoms in excess of the bare requirements to fulfill the DSM-IV } \\
\text { diagnostic criteria for PPD and cause a major impairment of } \\
\text { social/occupational functioning. }\end{array}$ \\
\hline $\begin{array}{l}\text { Individual interpersonal therapy or group counselling, and } \\
\text { couples therapy if marital discord is a factor. Also, patient education } \\
\text { materials should be provided for the mother and spouse (16) } \\
\text { " If there is no response to talk therapy, consider adding a SSRI or } \\
\text { tricyclic antidepressant*. } \\
" \text { If the depression worsens, or there are suicidal/infanticidal } \\
\text { thoughts, or symptoms of psychosis, or inadequate response to an } \\
\text { antidepressant, then refer to a psychiatrist (16). }\end{array}$ & $\begin{array}{l}\text { " Consider a SSRI or tricyclic antidepressant* +/- individual } \\
\text { interpersonal therapy or group counselling, and couples therapy if } \\
\text { marital discord is a factor. Also, patient education materials should } \\
\text { be provided for the mother and spouse (16) } \\
\text { " If the depression worsens, or there are suicidal/infanticidal } \\
\text { thoughts, or symptoms of psychosis, or inadequate response to an } \\
\text { antidepressant, then refer to a psychiatrist (16) }\end{array}$ \\
\hline
\end{tabular}

\section{Notes on antidepressant administration:}

" Selective serotonin-reuptake inhibitors (SSRIs) (25,27), venlafaxine (28) and tricyclic antidepressants (TCAs) (29) have been shown to be more effective than placebo for treating PPD, and are therefore considered to be appropriate therapy for PPD. Fluoxetine was shown to be as effective as psychotherapy for treating PPD (27).

" SSRIs or venlafaxine should be considered as first-line drug therapy rather than TCAs because they are associated with a lower risk of toxic effects in patients who have taken an overdose (3). Also, women with PPD are more likely to have a response to SSRIs or venlafaxine than to TCAs $(25,28,29)$ However, TCAs should be considered for women who have responded to them in the past $(38)$.

" Administration of TCAs or SSRIs is not contraindicated during breastfeeding. However, small amounts of the drugs do reach the infant via breast milk. Since the long-term effects of this exposure are not known, parents should make informed decisions that are documented in their medical records. It should be emphasised to women with moderate/severe depression, women who have not responded to psychotherapy, and women who are suicidal, infanticidal or psychotic that the benefits of taking antidepressants are considered to outweigh the risks of exposure to the infant.

" If an exposed infant seems irritable, plasma concentration of the drug should be determined and appropriate dosage adjustments made (38).

" Antidepressant therapy should be started at the starting doses used for nonpuerperal depression. Once a full remission is achieved, therapy should continue for a minimum of six months, in order to prevent relapse (38). 
referral for individual and relationship therapy if functioning or insight remains seriously impaired.

\section{REFERENCES}

1. O'Hara MW. Postpartum Depression. In: Alloy LB, editors. Series in Psychopathology. New York: Springer-Verlag; 1995.

2. Kumar R, Robson KM. A prospective study of emotional disorders in childbearing women. Br J Psychiatry. 144:35-47; 1984

3. O'Hara MW, Neunaber DJ, Zekoski EM. A prospective study of postpartum depression: prevalence, course, and predictive factors. J Abnormal Psychology. 158-171;1984.

4. American Psychiatric Association. Diagnostic and statistical manual of mental disorders. 4th ed. Washington, D.C.: American Psychiatric Association, 1994.

5. Harris B, Lovett L, Smith J, et al. Cardiff puerperal mood and hormone study. III. Postnatal depression at 5 to 6 weeks postpartum, and its hormonal correlates across the peripartum period. Br J Psychiatry. 168(6):739-744; 1996.

6. Stowe ZN, Nemeroff CB. Women at risk for postpartum-onset major depression. Am J Obstet Gynecol. 173(2):639-645;1995.

7. McEwen BS. Ovarian steroids have diverse effects on brain structure and function. In: Hammar GBaM, editors. The Modern Management of Menopause. New York: Parthenon Publishing; 1993.

8. Hendrick, V, Altshuler, L, Suri, R. Hormonal changes in the postpartum and implications for postpartum depression. Psychosomatics: Journal of Consultation Liasion Psychiatry. 39(2): 93-101;1998.

9. Cooper PJ, Murray L. The course and recurrence of postnatal depression. Br J Psychiatry 166:191-95;1995.

10. Boyce P. Personality dysfunction, marital problems and postnatal depression. In: Cox J, Holden J, editors. Perinatal psychiatry: use and misuse of the Edinburgh Postnatal Depression Scale. London, England: Gaskell, 1994.

11. Cogill SR, Caplan HL, Alexandra H, Robson KM, Kumar R. Impact of maternal postnatal depression on cognitive development of young children. BMJ 292:1165-67;1986.

12. Whiffen VE, Gotlib IH. Infants of postpartum depressed mothers: temperament and cognitive status. J Abnorm Psychol 98:274-97;1989.

13. Whitton A, Warner R, Appleby L. The pathway to care in postnatal depression: women's attitudes to post-natal depression and its treatment. Br J Gen Pract 46:427-28;1996.

14. Hirschfield RMA, Keller MB, Panico S, et al. The national depressive and manic-depressive association consensus statement on the undertreatment of depression. JAMA 277:33340;1997.

15. Yawn, B. Recent tragedies focus attention on postpartum depression. http://www.ama-assn.org/sci-pubs/amnews/ pick_01/hlsb0730.htm

16. Epperson, C. N. Postpartum Major Depression: Detection and Treatment. American Family Physician April 15:22472259;1999.

17. Cox, JL. Postnatal Depression. Churchill Livingston; 1986

18. Georgiopoulos, AM, Bryan, TL, Woolan, P.,and Yawn, BP. Routine Screening for Postpartum Depression. The Journal of Family Practice 50, No. 2;2001.
19. Cox JL, Holden JM, Sagovsky R. Detection of postnatal depression: development of the 10-item Edinburgh Postnatal Depression Scale. Br J Psychiatry 150:782-86;1987.

20. O'Hara MW. Postpartum depression: identification and measurement in a cross-cultural context. In: Cox J, Holden J, editors. Perinatal psychiatry: use and misuse of the Edinburgh Postnatal Depression Scale. London, England: Gaskell; 1994.

21. Schaper AM, Rooney BL, Kay NR, Silva PD. Use of the Edinburgh Postnatal Depression Scale to identify postpartum depression in a clinical setting. J Reprod Med 39:620-24;1994.

22. Boyce P, Stubbs J, Todd A. The Edinburgh Postnatal Depression Scale: validation for an Australian sample. Aust N Z J Psychiatry 27:472-6;1993.

23. Murray L, Carothers A. The validation of the Edinburgh Postnatal Depression Scale on a community sample. Br J Psychiatry. 157:288-90;1990.

24. Harris B, Huckle P, Thomas R., John S., Fung H. The use of rating scales to identify postnatal depression. Br J Psychiatry. 154: 813-817;1989.

25. Stowe ZN, Casarella J, Landry J, Nemeroff CB. Sertraline in the treatment of women with postpartum major depression. Depression 3:49-55;1995.

26. Epperson CN, McDougle CJ, Ward-O'Brien D, Price LH. A controlled study of sertraline versus placebo in the treatment of postpartum depression: preliminary findings [Abstract 76.3]. Soc Neurosci 22:179;1996.

27. Appleby L, Warner R, Whitton A, Faragher B. A controlled study of fluoxetine and cognitive-behavioural counselling in the treatment of postnatal depression. BMJ 314:932-6;1997.

28. Cohen LS, Viguera AC, Bouffard, et al. Venlafaxine in the treatment of postpartum depression. J. Clin. Psychiatry. 62:592$596 ; 2001$

29. Wisner KL, Peindl KS, Gigliotti TV. Tricyclics vs SSRIs for postpartum depression. Arch Womens Mental Health. 1:18991;1999.

30. Gerstein HC. How common is postpartum thyroiditis? A methodologic overview of the literature. Arch Intern Med 150:1397-400;1990.

31. Rouse, T., Tang, G., Torgerson, C., and Van Spall, H. Essentials of Clinical Examination Handbook. 3rd Ed. The Medical Society, Faculty of Medicine, U. of Toronto, 2000.

32. Beck CT. A meta-analysis of predictors of postpartum depression. Nursing Res. 45:297-303;1996.

33. Llewellyn AM, Stowe ZN, Nemeroff CB. Depression during pregnancy and the puerperium. J Clin Psychiatry. 58(suppl 15):26-32;1997.

34. O'Hara MW. Social support, life events, and depression during pregnancy and the puerperium. Arch Gen Psychiatry 43:569$73 ; 1986$.

35. Czarkowski, K. Postpartum Depression and the "Baby Blues". American Family Physician April 15:1259-1263;1999

36. Misri, S. The impact of partner support in the treat.ment of postpartum depression. Can J Psychiatry. 45(6): 554-8;2000.

37. Paykel ES, Emms EM, Fletcher J, Rassaby ES. Life events and social support in puerperal depression. Br J Psychiatry 136:33946;1980.

38. Wisner, K.L., Parry, B.L. and Piontek, C.M. Postpartum Depression. NEJM. 347, No. 3:194-199;2002.

Aaron Keshen is a 3rd year medical student from Dalhousie University, Halifax, N.S. Dr. Joanne L. MacDonald, MD, FRCPC, is with the Reproductive Psychiatry Consultation Service, Maternal Health Program, IWK Health Center, Halifax, N.S. 